\title{
ELECTROCHEMICAL CHARACTERIZATION OF LABORATORY FABRICATED BROMIDE ION SELECTIVE ELECTRODE
}

\section{Armila Rajbhandari (Nyachhyon), Krishna Manandhar and Raja Ram Pradhananga}

Journal of Institute of Science and Technology

Volume 21, Issue 1, August 2016

ISSN: 2469-9062 (print), 2467-9240(e)

Editors:

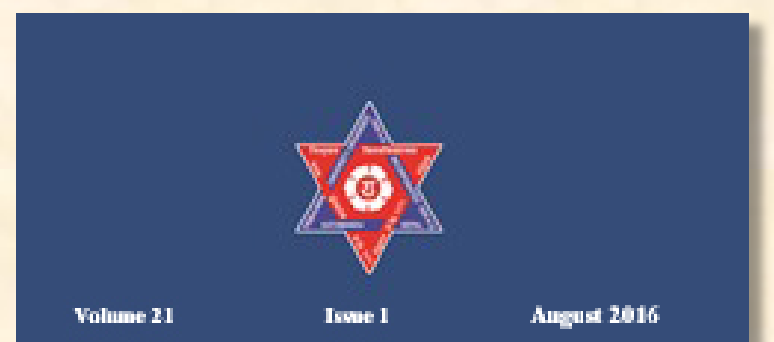

JOURNAL OF INSTITUTE OF SCIENCE AND TECHNOLOGY

Prof. Dr. Kumar Sapkota

Prof. Dr. Armila Rajbhandari

Assoc. Prof. Dr. Gopi Chandra Kaphle

JIST, 21 (1), 76-81 (2016)

Publiblied by

Institute of Science and Teehnology

Tribhuvan University

Kirtipur, Kathmanda, Nepal

Published by:

Institute of Science and Technology

Tribhuvan University

Kirtipur, Kathmandu, Nepal 


\title{
ELECTROCHEMICAL CHARACTERIZATION OF LABORATORY FABRICATED BROMIDE ION SELECTIVE ELECTRODE
}

\author{
Armila Rajbhandari (Nyachhyon),", Krishna Manandhar and Raja Ram Pradhananga \\ Central Department of Chemistry, Tribhuvan University, Kirtipur, Nepal, \\ *Corresponding email: armila3@yahoo.com
}

\begin{abstract}
Bromide ion selective electrode (Br-ISE) have been successfully fabricated in the laboratory. The polycrystalline $\mathrm{Ag}_{2} \mathrm{~S}-\mathrm{AgBr}$ membrane material of $\mathrm{Br}$-ISE was prepared by co-precipitation of silver sulphide and silver bromide from aqueous solution and was characterized by X-ray diffractometry (XRD). XRD results showed that material is in mixed phase state having $\mathrm{Ag}_{3} \mathrm{SBr}, \mathrm{Ag}_{2} \mathrm{~S}$ and $\mathrm{AgBr}$. Scanning electron microscopy (SEM) has been used to study the texture of the surface. The potentiometric response has been investigated by 2 electrode system whereas 3 electrode systems have been used for electrochemical impedance spectroscopy (EIS). The electrode was found to behave well up to the bromide concentration of $1 \times 10^{-5} \mathrm{M}$ with a Nernstian slope of $58 \mathrm{mV}$ per decade change in bromide ion concentration. The selectivity coefficient of electrode containing bromide ion in the presence of $\mathrm{I}^{-}$and $\mathrm{Cl}^{-}$ions was found to be 3.98 and $8 \times 10^{-2}$, respectively indicating that $\mathrm{I}^{-}$and $\mathrm{Cl}$ - ions interfere in the response of bromide electrode to bromide ion. The EIS studies shows that the charge transfer process is the key mechanism that is going on at the electrode/ electrolyte interface and electrode/ back contact interface.
\end{abstract}

Keywords: $\mathrm{Ag}_{2} \mathrm{~S}-\mathrm{AgBr}$ electrode, Nernstian response, Selectivity coefficient, Electrochemical impedance Spectroscopy (EIS)

\section{INTRODUCTION}

Ion selective electrode (ISE) provides a convenient and quick analytical procedure for the estimation of ions in aqueous solutions that may be turbid, colored and contain additives (Mousavi et. al. 2000). Due to these advantages, it is used in different fields like analytical, pharmaceutical, environmental, biomedical, industrial fields and recognized as excellent analytical tool (Pungor et al., 1983, Barbosa et al.,1999, Bailey,1969). A number of commercial ISEs are available which are selective for various cations and anions (Bailey, 1969, Orion Research Inc., 1970). The ISE technique becomes so popular that the method of analysis with ISE has been adopted as a standard method for the analysis of water and waste water (Clesceri et al., 1998). Silver sulphide based ISEs are one of the earliest ISE that have been well characterized and used (Pungor et al., 1965, Bakker et al., 2002, Gabrielli et al., 1974). The method of preparation and characterization of membrane material and electrode has been kept as patent. The membrane composition is guarded as trade secrets. The membrane composition and electrode characterization in terms of different parameters like Nernstian response, response time, selectivity coefficient, detection range limit, texture study stability and measurement of impedance is in well addressed in literature. In our previous study (Rajbhandari et al., 2010), characterization of iodide selective electrodes (I-ISE) have been discussed. In this study, we have presented preparation and characterization of bromide ion selective electrode (Br-ISE). The surface morphology, phase composition have been discussed by SEM and XRD respectively. The EIS was used to investigate the mechanism that is going on at the electrode/electrolyte interface and electrode/ back contact interface of Br-ISE.

\section{MATERIALS AND METHODS \\ Reagents}

All the chemicals used were of analytical grade and all the solutions were prepared in distilled water. Silver nitrate was purchased from Sigma Aldrich and potassium bromide was purchased from Merck. A stock solution of $0.1 \mathrm{M} \mathrm{AgNO}_{3}$ and $0.1 \mathrm{M} \mathrm{KBr}$ were prepared after drying to $110^{\circ} \mathrm{C}$ for 1 hour. A stock solution of $0.1 \mathrm{M} \mathrm{Na}_{2} \mathrm{~S}$ ( $\mathrm{L} \mathrm{R}$ grade) was prepared and standardized with potassium iodate 
solution by standard method (Jeffery et al. 1996). Direct potentiometry was carried out by successive addition of bromide ion solution in $0.1 \mathrm{M} \mathrm{KNO}_{3}$, which was used as the background electrolyte.

\section{Instrumentation}

Potentials were measured by using OSAW- digital potentiometer (India) relative to a silver/silver chloride reference electrode. Scanning electron microscopy (SEM) characterization was performed with a KEYENCE REAL 3D System, VE-series, Japan at $5 \mathrm{kV}$ accelerating voltage. XRD analysis was performed to investigate the crystal phase of the electrode materials using an X'Pert MPD-OEC, Phillips X-ray diffractometer. The measurements were performed using $\mathrm{Cu} \mathrm{k} \alpha$ radiation at $40 \mathrm{kV}$ and $40 \mathrm{~mA}$. The electrochemical impedance measurements were performed using a BioLogic VSP electrochemical workstation. The impedance spectra were recorded in the frequency range between $10 \mathrm{mHz}$ to $200 \mathrm{kHz}$ at $10 \mathrm{mV}$ perturbing signal and Z-view software (version $2.6 \mathrm{~b}$ ) was used for evaluating the impedance spectra.

\section{Preparation of membrane material and fabrication of electrode}

The $\mathrm{Ag}_{2} \mathrm{~S}-\mathrm{AgBr}$ composite material was prepared by co-precipitation technique. Desired mole ratio of $\mathrm{Ag}_{2} \mathrm{~S}: \mathrm{AgBr}$ membrane was obtained by taking appropriate moles of aqueous solution of $\mathrm{Na}_{2} \mathrm{~S}$ and $\mathrm{KBr}$ in which slight excess of aqueous solution of $\mathrm{AgNO}_{3}$ was added. The Reaction is given in equation (1).

$\mathrm{KBr}+\mathrm{Na}_{2} \mathrm{~S}+3 \mathrm{AgNO}_{3} \rightarrow \mathrm{Ag}_{2} \mathrm{~S}+\mathrm{AgBr}+$ $2 \mathrm{NaNO}_{3}+\mathrm{KNO}_{3}$

In this study, 1:1 mole percent of $\mathrm{Ag}_{2} \mathrm{~S}$ : $\mathrm{AgBr}$ was prepared.

The co-precipitate of $\mathrm{Ag}_{2} \mathrm{~S}-\mathrm{AgBr}$ was filtered and pretreated by washing with distilled water and acetone. The material thus obtained was dried at $110^{\circ} \mathrm{C}$ for 6 hours and ground to fine powder in an agate mortar. The size was controlled by sieving with $106 \mu \mathrm{m}$ sized sieve. Then powder was dried to about $60^{\circ} \mathrm{C}$ for 15 minutes and then about $1.5 \mathrm{gm}$ powder was taken in $\mathrm{KBr}$ pellet making machine. The 10 tones $/ \mathrm{cm}^{2}$ of pressure was applied for 15 minutes to make a pellet. The pellet was removed carefully from the die and was again dried at $110^{\circ} \mathrm{C}$ for an hour. The prepared pellet was then mounted in a polypropylene tube with the help of Araldite (Ciba-Geigy) and back contact was made with silver epoxy conducting paint with silver disk in which a copper wire was soldiered. The electrode was then abraded carefully with 1000 to 2000 grit sized silicon carbide paper to have smooth surface texture and finally sonicated in distilled water. A digital picture of laboratory prepared $\mathrm{Ag}_{2} \mathrm{~S}-\mathrm{AgBr}$ powder, pellet and of Br-ISE are shown in Fig.(1).

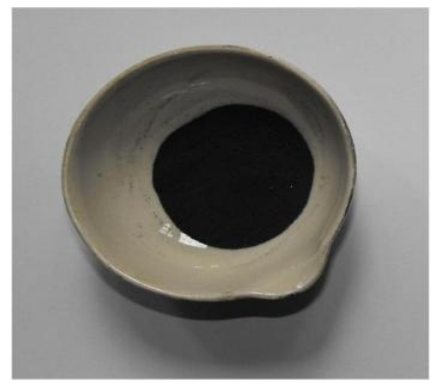

(a)

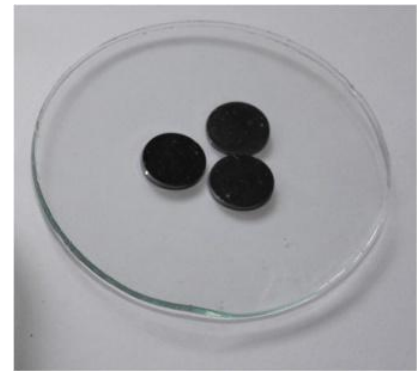

(b)

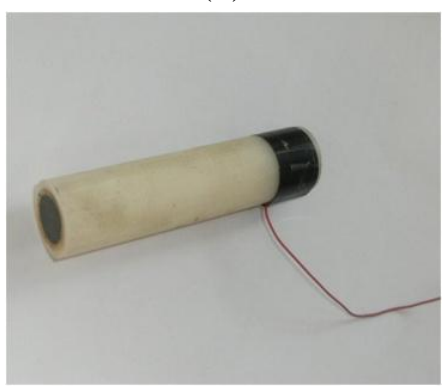

(c)

\section{Fig.1: Digital photograph of (a) $\mathrm{Ag}_{2} \mathrm{~S}: \mathrm{AgBr}$ powder, (b) pellet and (c) Br-ISE.}

\section{RESULTS}

\section{Characterization of the membrane materials}

Crystalline phase of laboratory prepared composite $\mathrm{Ag}_{2} \mathrm{~S}-\mathrm{AgBr}$ material was studied by XRD technique. XRD pattern of $\mathrm{Ag}_{2} \mathrm{~S}-\mathrm{AgBr}$ having 1:1 composition is shown in Fig. 2. The sharp diffraction peaks at $31.5^{\circ}, 33.6^{\circ}, 34.38^{\circ}, 36.78^{\circ}$, and $37.78^{\circ}$ were observed. These diffraction peaks are matched with that of $\mathrm{Ag}_{2} \mathrm{~S}, \mathrm{AgBr}$ and $\mathrm{Ag}_{3} \mathrm{SBr}$ compound according to the assignments based on the JCPDS data. The surface texture of polished $\mathrm{Ag}_{2} \mathrm{~S}-\mathrm{AgBr}$ pellet was studied by SEM technique. 
SEM picture of $1: 1$ pellet was taken at $5 \mathrm{kV}$ of accelerating voltage and are shown in Fig. 3.

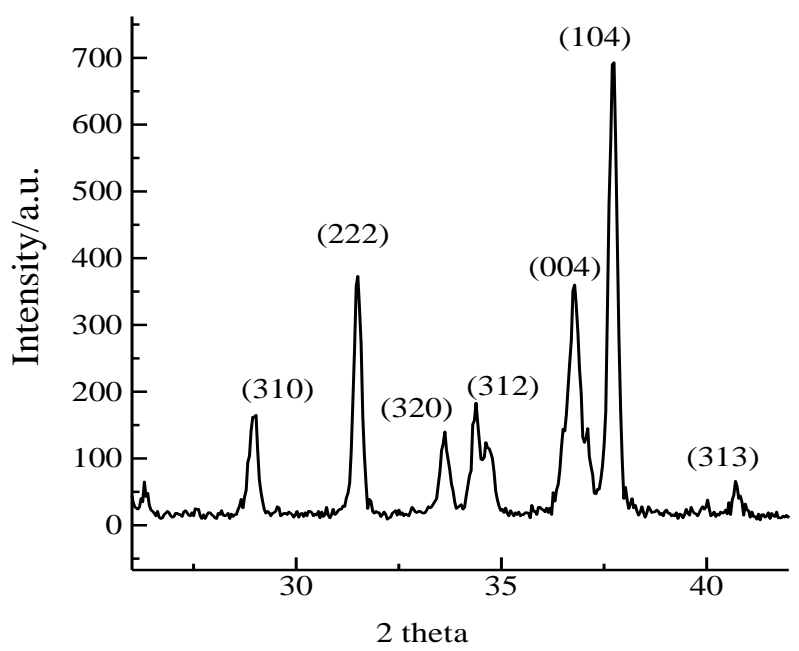

Fig. 2: XRD pattern of $\mathrm{Ag}_{2} \mathrm{~S}$-AgBr membrane. The intense peaks of $\mathrm{Ag}_{3} \mathrm{SBr}$ are clearly seen.

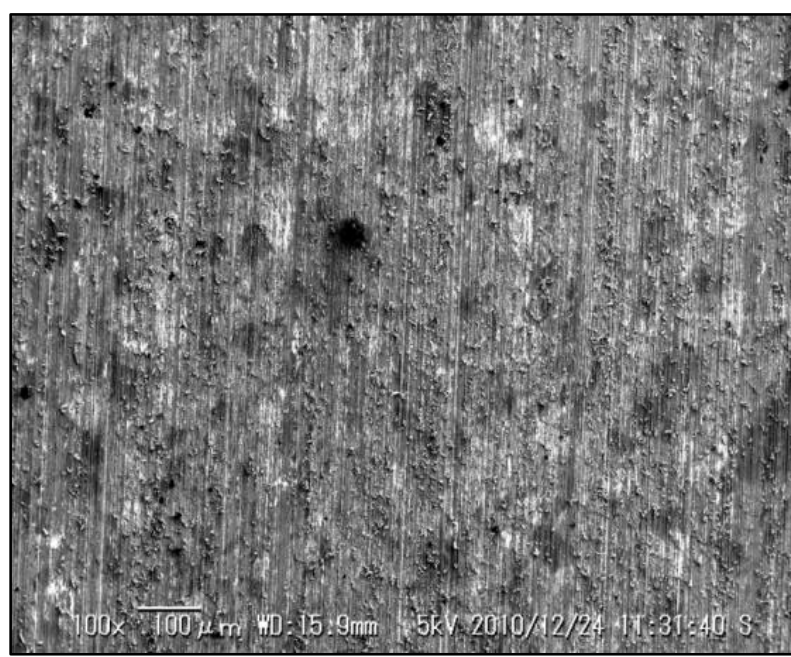

Fig. 3: SEM pictures of $\mathrm{Ag}_{2} \mathrm{~S}-\mathrm{AgBr}$ membrane Potentiometric characterization of the electrode.

The electrode was potentiometrically characterized by measuring the known concentration of $\mathrm{Br}$ - ion in the range of $10^{-1}$ to $10^{-6} \mathrm{M}$. Appropriate spikes of bromide were introduced into the cell containing $0.1 \mathrm{M} \mathrm{KNO}_{3}$ as background electrolyte and corresponding potentials were recorded. Figure 4 shows the potentiometric responses of Br-ISE to bromide ions. All measurements were carried out at constant stirring condition. In the plot, the points are the experimental values and the line is the line of best fit computed from the regression analysis.

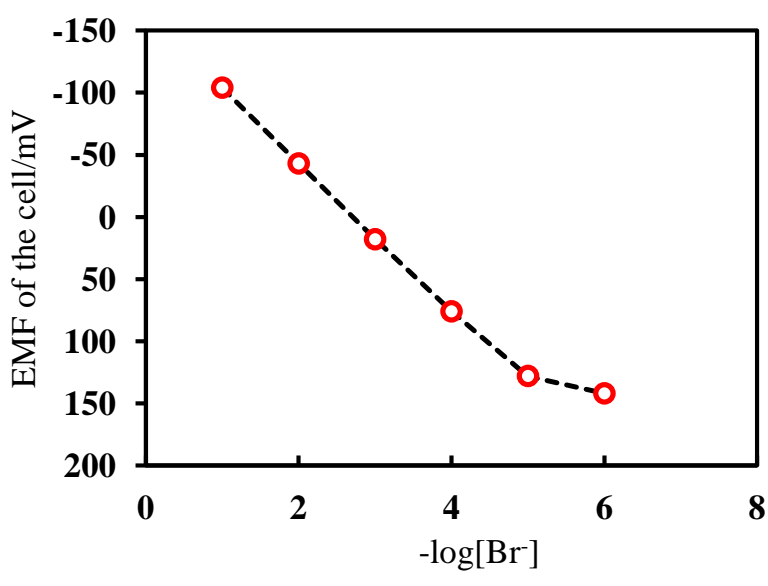

Fig. 4: EMF of the cell/mV as a function of -log [Br] The response time of the electrode.

In order to measure the response time of the Br-ISE, a 10 fold change in the $\mathrm{Br}$ - concentration was made while measuring the potential every ones till a constant potential value was obtained. The time dependence curve of Br-ISE 1:1 is shown in Fig. 5.

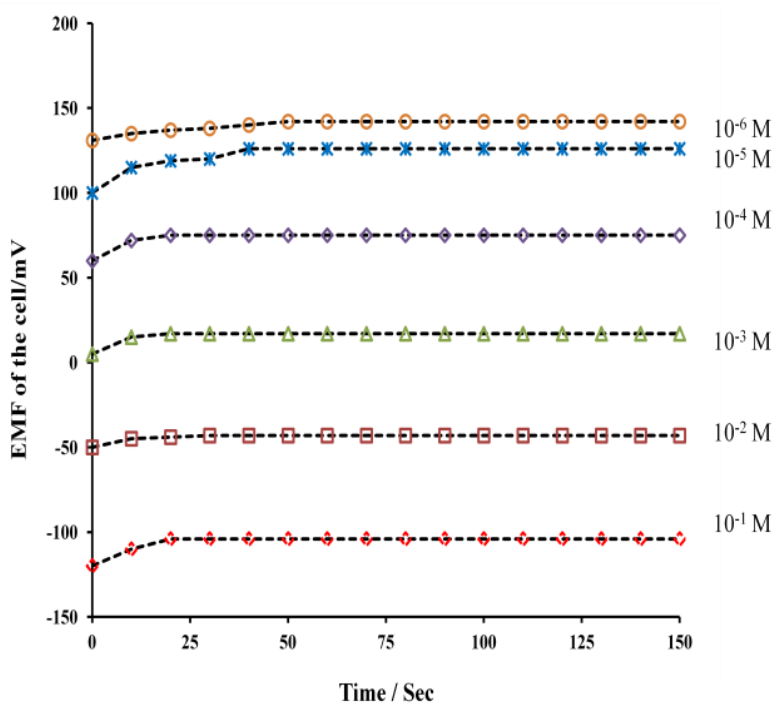

Fig. 5: EMF of the cell/mV as a function of time in sec Interference studies.

The effect of interfering ions is generally expressed in terms of potentiometric selectivity coefficients $\mathrm{K}_{\mathrm{A}, \mathrm{B}}^{\mathrm{pot}}$ which are expressed in Nicholsky-Eisenmsnn equation (2) (IUPAC, Recommend., 1994)

$\mathrm{E}=\mathrm{E}_{0}+\mathrm{RT} / n_{A} \mathrm{~F} \ln \left(a_{A}+\sum K^{p o t}{ }_{A, B}\left(a_{B}\right){ }_{A}{ }^{\prime}{ }_{B}{ }_{B}\right)$--- (2) Where $a_{A}$ and $a_{B}$ are the activities of main and interfering ions having charges $n_{A}$ and $n_{B}$ respectively, $E_{0}$ is standard potential of the electrode and $K^{p o t}{ }_{A, B}$ is the selectivity coefficient which describes the relative sensitivity of 
determinant ion. Interferences due to iodide and chloride ions were studied by fixed interference method (IUPAC, Recommend., 1994).

In this method, the concentration of bromide ion was varied from $1 \times 10^{-1} \mathrm{M}$ to $1 \times 10^{-6} \mathrm{M}$ while the interfering ions were kept as constant of $10^{-3} \mathrm{M}$. The selectivity coefficient $K_{A, B}^{\text {pot }}$ was found to be i.e., $3.98,8 \times 10^{-2}$ for $\mathrm{I}^{-}$and $\mathrm{Cl}^{-}$respectively.

\section{Electrochemical Impedance Spectroscopic (EIS)} studies

Mechanistic studies regarding ion transport, electron transport or mixture of both mechanisms in Br-ISE was investigated by EIS technique. In this study, the electrochemical impedance was measured in the frequency range of $10 \mathrm{mHz}$ to 200 $\mathrm{kHz}$ at open circuit potential in $10^{-1} \mathrm{M} \mathrm{KNO}_{3}$ and $10^{-3} \mathrm{M} \mathrm{KBr}$ solutions. The influence of the electrolyte concentration and composition of membrane material was also studied. The model of electrode is drawn and is shown in the Fig 6. In figure, the frankel type of lattice defect in bulk membrane is also shown.

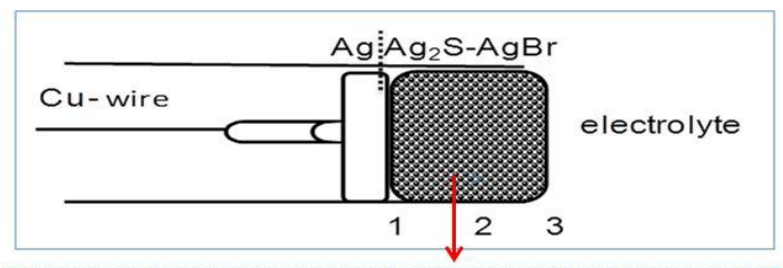

$\left[\begin{array}{lllllll}\mathrm{Ag}^{+} & \mathrm{Br} & \mathrm{Ag}^{+} & \mathrm{Br} & \mathrm{Ag}^{+} & \mathrm{Br} \\ \mathrm{Br} & \mathrm{Ag}^{+} & \mathrm{Br} & \mathrm{Ag}^{\prime} & \mathrm{Br} & \mathrm{Ag}^{+} \\ \mathrm{Ag}^{+} & \mathrm{Br} & \mathrm{Ag}^{+} & \mathrm{Br} & \mathrm{Ag}^{+} & \mathrm{Br} \\ \mathrm{Br} & \mathrm{Ag}^{+} & \mathrm{Br} & & & \\ \mathrm{Ag}^{+} & \mathrm{Br} & \mathrm{Ag}^{+},{ }^{+} & \mathrm{Br} & \mathrm{Ag}^{+} & \mathrm{Br}\end{array}\right.$

Fig 6: Model of present electrode and Showing (inset) Frankel type of lattice defect in $\mathrm{AgBr}$ crystal indicated by square box where silver ions can migrate from one interstitial site to other interstitial site.

To evaluate it the impedance data were obtained by EIS measurements. The Nyquist plots of Br-ISE in $10^{-1} \mathrm{M} \mathrm{KNO}_{3}$ and $10^{-3} \mathrm{M} \mathrm{KBr}$ solution are shown in Fig. 8 and 9 respectively. The equivalent circuit model after analysis is shown in Fig. 7.

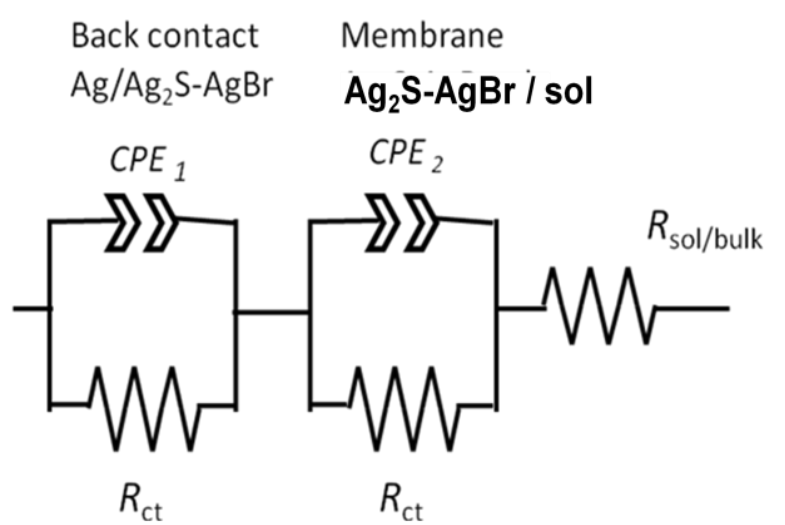

Fig.7: An equivalent circuit.

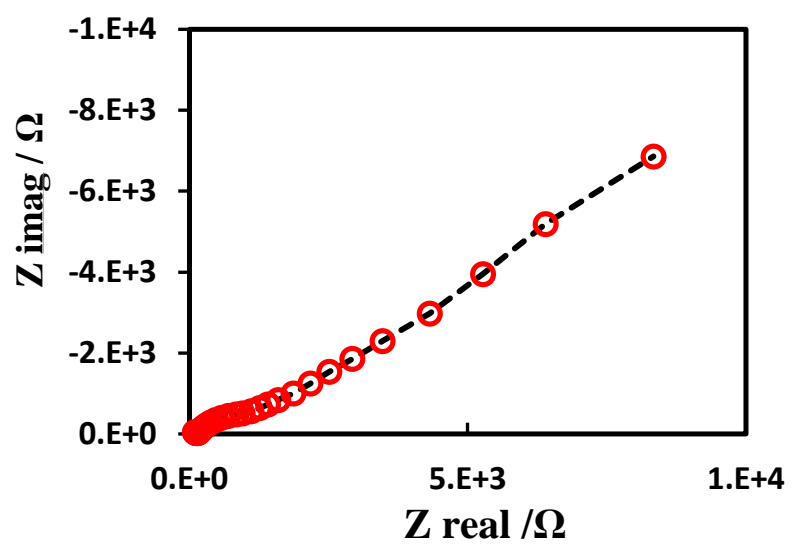

Fig. 8: Nyquist plot of impedance response obtained on Br-ISE in $10^{-1} \mathrm{M} \mathrm{KNO} O_{3}$ at open circuit potential.

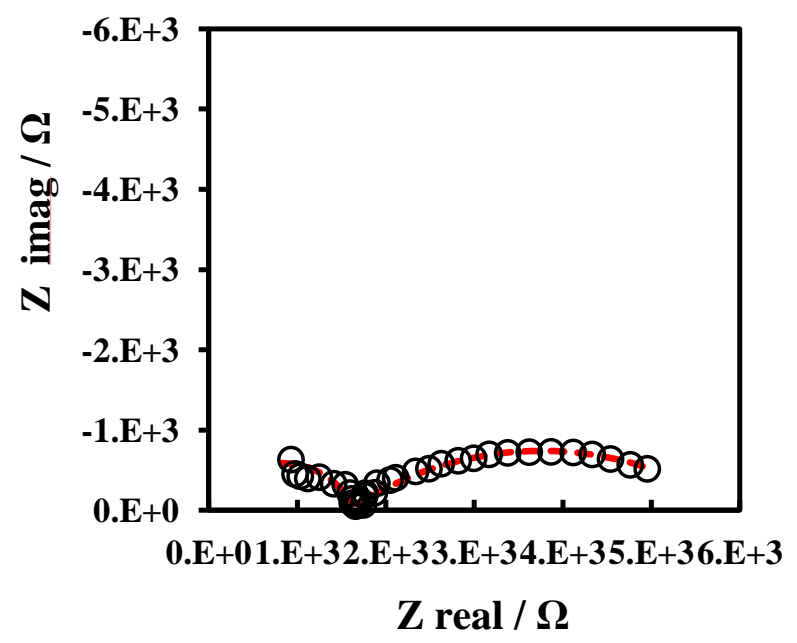

Fig. 9: Nyquist plot of impedance response obtained on $\mathrm{Br}-\mathrm{ISE}$ in $10^{-3} \mathrm{M} \mathrm{KBr}$ at open circuit potential. 


\section{Stability of electrode}

The stability of electrode was investigated. The study found that when the $\mathrm{Ag}_{2} \mathrm{~S}-\mathrm{AgBr}$ membrane is soaked for a long time ( 24 hours) in concentrated bromide solution, the electrode lost its performance, but showed satisfactory potential response after the membrane is repolished.

\section{DISCUSSION}

The $\mathrm{Ag}_{2} \mathrm{~S}-\mathrm{AgBr}$ material prepared in laboratory by co-precipitation technique, was characterized by XRD (Fig. 2) in which the sharp diffraction peaks at $31.5^{\circ}, 33.6^{\circ}, 34.38^{\circ}, 36.78^{\circ}$, and $37.78^{\circ}$ were observed, which are matched with that of $\mathrm{Ag}_{2} \mathrm{~S}$, $\mathrm{AgBr}$ and $\mathrm{Ag}_{3} \mathrm{SBr}$ compound according to the assignments based on the JCPDS data showed that the (320), (312), (004), (104), (222) crystal planes could be allocated for $\mathrm{Ag}_{3} \mathrm{SBr}$ whereas crystal plane (310) is allocated for $\mathrm{Ag}_{2} \mathrm{~S}$ and minor peaks of $\mathrm{AgBr}$ were also observed. The presence of $\mathrm{Ag}_{3} \mathrm{SBr}$ along with $\mathrm{Ag}_{2} \mathrm{~S}$ and $\mathrm{AgBr}$ shows that the materials are crystalline and in mixed phase state. The SEM picture of 1:1 pellet (Fig. 3) shows that the surface texture is found to be smooth, lustrous.

The laboratory fabricated $\mathrm{Ag}_{2} \mathrm{~S}-\mathrm{AgBr}$ electrode which was analyzed potentiometrically (Fig. 4), gives a linear response with respect to $-\log \left[\mathrm{Br}^{-}\right]$in the concentration range of $1 \times 10^{-1} \mathrm{M}$ to $1 \times 10^{-6} \mathrm{M}$ with slope of $58 \mathrm{mV}$. In the lower concentration range the curves however start to deviate from linearity. Similarly, the time response curve (Fig. 5) shows that the response of the electrode with change in the concentration of the solution was found to be fast and the system attained equilibrium potential within less than $20 \mathrm{sec}$ in all the concentration range. All the measurements were made at constant temperature with constant stirring of the solution. The results thus, obtained are indicative of a rapid diffusion achievement of equilibrium between the aqueous layer and the membrane. The selectivity coefficient $K_{A, B}^{p o t}$ was found to be i.e., $3.98,8 \times 10^{-2}$ for $\mathrm{I}^{-}$and $\mathrm{Cl}^{-}$ respectively. The higher selectivity coefficient value showed that the response of Br-ISE is adversely affected by the presence of iodide and also affected by chloride ions. The AgI $\left(K s p=0.9 \times 10^{-16}\right)$ is less soluble than $\mathrm{AgBr}$ $\left(K s p=7.7 \times 10^{-13}\right)$ So it is obvious that iodide interferes during potential measurement. But though the solubility value of $\mathrm{AgCl}\left(K s p=1.5 \times 10^{-10}\right)$ higher than $\mathrm{AgBr}$, chloride interferes when there is 1000 times higher chloride concentration in solution. It may also be due to the similarity in the crystal structures of silver bromide and silver chloride. The chloride ions may get adsorbed in the lattice of silver bromide. Those adsorbed chloride ions then obviously interfere during potential measurement.

Regarding to electrochemical characterization, in our previous study, we have discussed that the all solid state ISE can be considered to be consists of 3 distinct regions- the silver back contact/membrane interface, the bulk membrane, and membrane/ electrolyte interface (Rajbhandari et al., 2010). On this basis, the model of electrode is drawn and is shown in the Fig 6. In figure, the frankel type of lattice defect in bulk membrane is also shown.

The electrochemical reaction that is going on at electrode /electrolyte interface is typically analogous to electronic circuit having a special combination of resistors and capacitors (Bard et al., 1980). To evaluate it the impedance data were obtained by EIS measurements. The Nyquist plots of $\mathrm{Br}$-ISE in $10^{-1} \mathrm{M} \mathrm{KNO}_{3}$ and $10^{-3} \mathrm{M} \mathrm{KBr}$ solution are shown in Fig. 8 and Fig. 9 respectively. In the figure, points are the experimental values. The total impedance observed is $1.1 \times 10^{4} \mathrm{ohm}$ in $10^{-1} \mathrm{M}$ $\mathrm{KNO}_{3}$ electrolyte whereas in higher concentration of bromide $\left(10^{-3} \mathrm{M} \mathrm{KBr}\right)$ it is found to be $5 \times 10^{3} \mathrm{ohm}$ showing two time constants indicating by two capacitive loops, small one at higher frequency region and second at low frequency region and were fitted to the equivalent circuit shown in Fig. 7. This distinct semicircle at high frequency region due to bulk properties of membrane with bulk resistance and capacitance are mainly independent on experimental conditions. It represents for silver back contact and membrane as described by Bralic (Bralic et al., 1994) and Martinhohn (Martinhon et al., 2006). The second capacitive loop at low frequency region bulk resistance and capacitance are mainly dependent on electrolyte used and other experimental conditions. This loop was fitted with both the Warburg diffusion and an RC circuit component. It was found that a good fitting was observed by using RC circuit i.e., the charge transfer resistance in parallel to capacitance, in $10^{-}$ ${ }^{1} \mathrm{M} \mathrm{KNO}_{3}$ solution and in $10^{-3} \mathrm{M} \mathrm{KBr}$ solution. This is in tune with previous study of I-ISE (Rajbhandari et. al. 2010).

Figure 7 represents the equivalent circuit corresponding to the model of the electrode shown in Fig. 6. The lines in Fig 8-9 show the fitted results by using equivalent circuit in Fig 7. It is obvious from the experiment that a good fitting was obtained. 
The stability experiment results indicated that when the electrode lost its performance, the method of repolishing is the satisfactory way to have good potential response by electrode.

\section{CONCLUSION}

An efficient bromide ion sensitive electrode were prepared by co-precipitation of $\mathrm{AgBr}$ on $\mathrm{Ag}_{2} \mathrm{~S}$ and found to be an excellent potentiometric sensor for the determination of bromide ion in aqueous solution. The electrode shows Nernstian response with respect to bromide ion upto $1 \times 10^{-5} \mathrm{M}$ concentration. The presence of $\mathrm{I}^{-}$and $\mathrm{Cl}^{-}$interferes during bromide response. The response time is very fast in all concentration range tested. The EIS results clearly showed that mixing of silver sulphide with silver bromide decreases the membrane resistance by a few orders of magnitude. It showed charge transfer mechanism for electrochemical reaction that is going on electrode electrolyte interface.

\section{ACKNOWLEDGEMENTS}

This research work was supported by a grant from Nepal Academy of Science and Technology (NAST), Institute of Science and Technology (IOST), Tribhuvan University. We acknowledge Tsuru-Nishikata Lab, Tokyo Institute of Technology (TIT), Japan for recording impedance.

\section{REFERENCES}

Bailey, P. L., 1969. Analysis with Ion Selective Electrodes. Heyden and Son, London.

Bakker, E., Telting-Diaz, M. 2002. Electrochemical Sensors. Analytical Chemistry 74: 2781-2800.

Barbosa, J., Barron, D., Butti, S., \& Marques, I. 1999. Assignment of $\mathrm{pHs}$ values of reference buffer solutions for standardization of potentiometric sensors in THF-water. Polyhedron 18: 3361-3367.

Bard, A. J., Faulker, L. R. 1980. Electrochemical Methods-Fundamentals and Applications. Wiley, New York.
Bralic, M., Radic, N., Brinic, S., Generalic, E. 1994. Fluoride electrode with $\mathrm{LaF}_{3-}$ membrane and simple disjoining solid-state internal contact. Croatica Chemica Acta 67: 543-551.

Clesceri L. S., Greenberg A. E. and Eaton A. D. 1998. Standard methods for the Examination of Water and Wastewater, $20^{\text {th }}$ Edition, APHA 1015 Fifteenth street, NW Washington, DC 20005-2605.

Gabrielli C., Keddam M. 1974. Progres recents dans la mesure des impedances electrochimiques en regime sinusoidal. Electrochimica Acta 19: 355-362.

IUPAC, 1994. Recommendations for nomenclature of ion selective electrodes. Pure and Applied Chemistry 66: 2527-2536.

Jeffery, G. F., Bassett, J., Mendham, J., Denney, R.C. 1996. Vogel's Textbook of Quantitative chemical analysis, $5^{\text {th }}$ Edition, ELBS, Longman, London.

Martinhon, P. T., Carrenno, J., Sousa, C. R., Barcia, O. E., Mattos, O. R. 2006. Electrochemical impedance spectroscopy of lead (II) ion selective solid state membranes. Electrochimica Acta 51: 3022-3028.

Mousavi, M. F., Alizadeh, N., Shamsipur, M. and Zohar, N. 2000. A new PVC based 1,10 dibenzyl 1,10- diaza -18 -crown -6 selective electrode for detecting nickel (II) ion. Sensors and Actuaters. B 66: 98.

Orion Research Inc., 1970. Newslett. 2: 41.

Pungor, E. and Havas, J., Toth, K. 1965. Von elektroden in der chemischen Analyse. Zeitung fur Chemie Analytica Chemica 5: 914.

Pungor, E., Toth, K., Klatsmanyi, P. G., Izutsu, K. 1983. Application of ion selective electrodes in nonaqueous and mixed solvents. Pure Applied Chemistry 55: 2029-2065.

Rajbhandari (Nyachhyon), A., Yadav, A. P., Manandhar, K. and Pradhananga, R. R. 2010. Characterization of homemade iodide selective. Talanta 82:1448-1454. 